\title{
HOMEOWNERSHIP AS A CONSTRAINT ON ASSET ALLOCATION
}

\author{
March, 2003 \\ Stephen Day Cauley \\ The Anderson School at UCLA \\ scauley@anderson.ucla.edu
}

\author{
Andrey D. Pavlov \\ Simon Fraser University and CIRANO \\ apavlovesfu.ca
}

Eduardo S. Schwartz

The Anderson School at UCLA

eschwarteanderson.ucla.edu

Special thanks to Eduardo Robinovich who provided crucial help in programming the numerical solutions and to Avi Bick for the insightful discussions related to the theoretical model. Bob Russel and the members of the Center for Scientific Computing at Simon Fraser University provided invaluable comments related to the numerical solution and access to great computational resources. 


\begin{abstract}
While home ownership provides a great deal of personal and social benefits, it poses a substantial constraint on individuals' asset allocation. By deciding how much home to buy, individuals limit their ability to adjust their asset allocations between residential real estate and other assets. Using a continuous-time framework we analyze the impact of this constraint on consumption, welfare, and post retirement wealth. For reasonable parameter values we find that the total loss of utility due to the home ownership constraint is equivalent to $6 \%$ of total net worth. This estimate ranges between 1 and $15 \%$ depending on the starting wealth, home value, and personal income of the agent. We further show that the home ownership constraint substantially alters the asset allocation to financial assets. For instance, if the value of the home exceeds the total net worth four times (not an unusual situation for many young households), the individuals' allocation to stocks drops in half due to the home ownership constraint. We also show that real estate investment has the additional benefit of providing a hedge against future increases in the cost of housing services. Even with this benefit, however, the total allocation to real estate would be substantially lower if individuals could freely adjust their investment in real estate.
\end{abstract}




\section{Introduction}

Home ownership is an important part of the "American Dream." A broad range of state and federal government initiatives, from the income tax deductibility of mortgage interest expense to FHA loan guarantees, are designed to encourage home ownership. ${ }^{1}$ Nationally, the homeownership rate exceeds 67 percent. Personal preferences and financial incentives make homeownership desirable for most families. However, such wide homeownership may or may not be socially optimal.

Buying a home is a lumpy investment that places a constraint on the owner's asset allocation decisions. By deciding how much home to buy an individual limits their ability to adjust their asset allocations between residential real estate and other assets. In this paper we analyze the impact of this constraint on consumption, welfare and post retirement wealth. Understanding these implications is especially important today because of substantial concern about the future adequacy of the Social Security Trust Fund.

In this paper, we abstract from the housing choice decision and start by assuming a representative individual has irreversibly chosen the home to live in until retirement. We then investigate their optimal asset allocation decisions when subject to a homeownership constraint. Next, we consider the same individual's asset allocation decisions when they have the ability to sell, without cost, a fractional interest in their home. By comparing the asset allocation decisions and terminal wealth in these two cases, we estimate the differences in post-retirement wealth and the welfare gains potentially realizable if individuals' asset allocation were not subject to the home ownership constraint.

We employ a three state variable stochastic dynamic optimization to find the asset allocations and estimate the total expected utility in the two cases. The state variables are total net worth, value of the home in which the agent lives, and personal income. This methodology is particularly appropriate to analyze our asset allocation model because of the complex and time-varying constraints faced by a home owner.

\footnotetext{
${ }^{1}$ Glaeser and Shapiro (2002) investigate the effect of the income tax deductibility of home mortgage interest payments on homeownership.
} 
For realistic parameter values we find that a home owner would require a $6 \%$ increase in total net worth to achieve the same utility level as an individual not facing the asset allocation constraint. This compensation ranges between 1 and $15 \%$ of net worth over the state space we consider. Furthermore we find that home ownership substantially alters the asset allocation to financial assets. For instance, if the value of the home exceeds the total net worth four times (not an unusual situation for many young households), the individuals' allocation to stocks drops in half due to the home ownership constraint. At the same time, home ownership nearly doubles the amount of borrowing relative to the unconstrained case and reduces non-housing consumption. As expected, the required compensation and the differences in asset allocation between the two cases diminish with time.

Somewhat surprisingly we find that the evolution of wealth if all assets receive their expected rate of return through time is virtually identical in the two cases. Even though real estate tends to have lower total return then stocks, it can be purchased with higher leverage which can potentially increase the expected return on investment. In a stochastic environment, however, the evolution of wealth is very different in the two cases.

We also find evidence that the allocation to real estate in the unconstrained case includes a small but important hedging component consistent with the theoretical model of Sinai and Souleles (2002). In our model, an individual who is not subject to the home ownership asset allocation constraint has to pay rent proportional to the value of their home. Therefore, an investment in real estate serves as a hedge against future increases in the rent payments and adds to the benefits of holding real estate as a pure investment asset. Contrary to Sinai and Souleles (2002), we find that this hedging demand diminishes through time.

The remainder of this paper is divided into sections that: (1) review the relevant literature and highlight our major extensions to the literature; (2) describe the asset allocation problem faced by individuals who are subject to a homeownership constraint; (3) describe the same problem for individuals who are not subject to the constraint; (4) describe the data and numerical solution that are used to explore the implications of the homeownership constraint, (5) evaluate the effect of the constraint on post-retirement 
wealth and utility, and (6) summarize our findings and suggest direction for further research.

\section{Literature Background and Major Extensions}

Despite the vast literature on optimal portfolio choice, most papers do not consider the impact on asset allocation of an individual's investment in a home (i.e., a durable consumptions good). Three exceptions are Grossman and Laroque (1991), Flavin and Yamashita (2002) and Cocco (1999). Grossman and Laroque (1991) develop a theoretical model with a single illiquid durable consumption good (e.g., a house) from which an infinitely lived investor derives utility. The illiquidity derives from the fact that transaction costs are born when the good (house) is sold. In addition to the durable good the individual can invest in a risk free asset and a set of risky financial assets. At each time, the individual must decide whether to acquire a larger (smaller) house and how to allocate his or her remaining wealth among financial assets. Grossman and Laroque show that it is optimal for the individual to wait for large increases (decreases) in wealth to increase (decrease) their consumption of the durable consumption good. In addition, they conclude that transaction cost causes the individual to allocate a smaller portion of their financial wealth to risky assets than would occur if the individual could adjust home ownership continuously. This paper does not consider the risk and returns to an individual's investment in human capital when analyzing the optimal asset allocation.

Flavin and Yamashita (2002) study the impact of the portfolio constraint imposed by the consumption demand for housing on an individual's optimal holdings of financial assets. In addition to a house, the individual can invest in T-Bills, T-Bonds, stocks, and borrow through a mortgage loan. They use PSID data to explore the life cycle impact of the "housing constraint" (as reflected by the ratio of housing to net worth) on the individual's optimal holding of financial assets. The starting point of their analysis is the observed (from the PSID) ratio of housing to net worth. Flavin and Yamashita then use mean-variance analysis to characterize optimal portfolios of financial asset over the life cycle.

Cocco (1999) develops an empirically parameterized model of consumption and portfolio choice when there is an illiquid durable consumption good (a house). In this 
paper the individual purchases a home for the consumption services it provides. The value of the home is not stochastic. The individual has a stochastic income and can invest in two financial assets: a stock fund and Treasury bills. Cocco's portfolio optimization model is then used to predict the cross-sectional pattern of variation in the composition of wealth by age and net worth.

Within the last five years, Bertaut and Haliassos (1997), Guiso, Jappelli, and Terlizzesse (1996), Heaton and Lucas (1999), and Poterba and Samwick (1997) have empirically investigated the portfolio choice of households. The goal of this research was to understand how labor income affects the allocation of wealth among financial assets. Unfortunately, when dealing with household level data it is not easy to develop an appropriate treatment of the investment in real estate. Bertaut and Halliassos ignore the effect of housing altogether. Heaton and Lucas recognize the importance of housing and include them as regression variables. These papers do not provide theoretical justification for either excluding the consideration of real estate all together or including it in a partial equilibrium regression model.

This paper extends the work of Flavin and Yamashita (2002) and Cocco (1999) in several ways:

- we consider both uncertain income from human capital and risky investments in residential real estate whose returns may be highly correlated.

- implement continuous-time long-term strategic asset allocation optimization subject to a number of realistic investment constraints

- explicitly model the main characteristics of investment in one single real estate property

- $\quad$ explicitly model the borrowing constraints associated with mortgage loans and margin account investing.

The purpose of these extensions and of a number of other modeling choices is to develop a realistic picture of the impact of home ownership on asset allocation and postretirement wealth. The introduction of human capital to the portfolio optimization problem is particularly important if real estate is one of the available investment assets. Income levels and the value of homes are almost always sensitive to local economic conditions. For instance, if a regional economy is subject to a large negative shock, 
personal income (through hours of work or incidence of unemployment) and real estate values frequently decline in tandem. A homeowner facing such conditions can see the value of their two most important assets decline. Needless to say, this correlation can have serious negative implications for the overall risk of a homeowner's asset portfolio.

\section{Model}

We will consider a representative individual who has a working life and investment horizon of $T<\infty$ (e.g., 20 years to retirement). His or her objective is to maximize the present value of the expected utility from pre-retirement consumption and post-retirement wealth. The individual has recently purchased a home for a price $H$. The home is assumed to provide a constant flow of housing services. The quantity of house bought $(H)$ was determined by the individual's demand for housing services and the house's characteristics as an investment. The purchase was financed with a fixed interest rate, full recourse mortgage whose contracted interest rate equals sum of the real mortgage rate, $r$, and the constant known inflation rate $i{ }^{2}$ To capture the essence of the homeownership constraint, we assume the owner cannot sell the house until retirement at time $T .{ }^{3}$ In addition, the individual has total wealth $W>0$ that includes home equity and can be invested in a stock index and/or a money market fund. Finally, until retirement the individual has stochastic income $(y)$ derived from human capital.

In the remainder of this section we describe the assets and formalize the representative individual's asset allocation problem. Two cases are considered:

1. The base case where the individual is subject to the homeownership constraint, and

2. The benchmark case where investments in residential real estate are not constrained (i.e., any non-negative amount can be invested in housing).

We then compare the evolution of consumption and asset allocations. This comparison allows us to evaluate the effect of the constraint on post-retirement wealth and total welfare.

\footnotetext{
${ }^{2}$ We assume the loan is full recourse to eliminate consideration of the value of the option to default.

${ }^{3}$ What is relevant is not that the individual does not sell their house, but that the constraint on the individual's allocation decision imposed by homeownership does not change. For example, if the family moves, it moves to an equally valuable house with an equivalent loan to value ratio.
} 


\subsection{The Assets}

As was noted earlier, the individuals can investment in two types of financial assets: a stock index and a money market fund. Let $S_{t}$ denote the real value of the individual's investment in the non-dividend paying stock index fund at time $t{ }^{4}$ The dynamics of $S_{t}$ are given by:

$$
d S=\left(r+\mu_{S}\right) S d t+\sigma_{S} S d z_{S}
$$

where $\mu_{\mathrm{S}}$ represent the risk premium over the real mortgage interest rate, $r$, and $\sigma_{\mathrm{S}}$ the volatility of the index fund, both of which are positive constants. ${ }^{5}$

The money market fund pays a real non-stochastic rate of interest equal to the real mortgage interest rate, $r$. Analytically, deposits in the money market fund are equivalent to partial repayment of the mortgage loan. In this way a homeowner can effectively increase their equity in their home. ${ }^{6}$

Although, in our base case, the homeowner cannot sell their house until retirement, there is a housing market where similar properties are sold. This market provides information about the value of the housing portion of individual's portfolio. Let $H_{t}$ denote the real value of the house, which is assumed to evolve according to the stochastic process:

$$
d H=\mu_{H} H d t+\sigma_{H} H d z_{H}
$$

where $\mu_{\mathrm{H}}$ and $\sigma_{\mathrm{H}}$ are positive constants. Note that the flow of housing services received from home ownership is independent of the owner's equity position in the house. For

\footnotetext{
${ }^{4}$ Allowing the stock fund to pay dividends would not qualitatively change of our results

${ }^{5}$ Note that $\mu_{\mathrm{S}}$ is typically the risk premium over the risk-free rate of return. Here we take it to mean the risk-premium over the mortgage rate which is assumed to command a constant premium over the risk-free rate of interest.

${ }^{6}$ This assumption is made to simplify the analysis and avoid the possibility of arbitrage between the money market fund and the mortgage loan.
} 
this reason, the value of these services does not affect the individual's asset allocation decision. The correlation between the stock fund and home values is $\rho_{\mathrm{SH}}$, with $\sigma_{\mathrm{SH}}=\sigma_{\mathrm{S}} \sigma_{\mathrm{H}} \rho_{\mathrm{SH}}$ denoting the covariance between the processes.

The individual's real income (return on their investment in human capital), $y_{t}$, is also stochastic and evolves according to the following process for $t<T$ :

$$
\frac{d y}{y}=\mu_{y} d t+\sigma_{y} d z
$$

Let $\rho_{\mathrm{yH}}$ denote the correlation between income and the rate of home value appreciation, with $\sigma_{\mathrm{yH}}=\sigma_{\mathrm{y}} \sigma_{\mathrm{H}} \rho_{\mathrm{yH}}$ represents the corresponding covariance. The correlation between income and the return on the stock market is denoted by $\rho_{y S}$, with $\sigma_{y S}=\sigma_{y} \sigma_{S} \rho_{y S}$ being the corresponding covariance. By assumption, post retirement income, $t \geq T$, is zero.

\subsection{Asset Allocation Base Case}

As we noted above, investments in the money market fund pay a non-stochastic rate of interest equal to the real mortgage interest rate, $r$. Consequently, the individual's mortgage loan balance and investment in the money market fund can, and will, be consolidated in our analysis (i.e., the mortgage loan is equivalent to a negative balance in the money market fund).

In the base case, the individual's home cannot be sold until retirement. In other words, the investment in residential real estate is stochastic but constrained (i.e., exogenously determined). Consequently, individuals have to optimally decide what portion of their wealth not tied up in home equity to invest in the stock index and money market funds.

The individual's objective is to maximize, by the choice of the level of consumption and asset allocation, the sum of the present value of the expected utility from consumption until retirement and the expected utility of post-retirement wealth. ${ }^{7}$ Assuming isoelastic utility of wealth, the optimization at time $t$ is:

\footnotetext{
${ }^{7}$ As noted above, we assume the utility of housing services is separable. This assumption implies that housing services do not affect the optimization.
} 


$$
V\left(W_{t}, H_{t}, y_{t}, t\right)=\max E_{t}\left[\int_{t}^{T} e^{-k x} U\left(C_{x}\right) d x+e^{-k(T-t)} U_{T}\left(W_{T}\right)\right]
$$

where

$$
\begin{aligned}
U(x) & =\frac{x^{1-\gamma}}{1-\gamma}, \quad x \geq 0 \\
& =-\infty, \quad x<0,
\end{aligned}
$$

$C$ denotes consumption of non-housing services, $k$ is the homeowner's rate of time preference, and $\gamma$ is the risk aversion parameter.

Our representation of the utility of post-retirement wealth, $U_{T}\left(W_{T}\right)$, is designed to reflect the trade off between pre and post retirement consumption. To capture the essence of aging, while maintaining computational tractability, we assume the individual has a known time horizon (life), $R$, after retirement, (e.g.,20 years). At retirement, the individual sells his or her house and cashes-in his or her investment in the stock index fund. For simplicity we assume that the individual is able to avoid capital gains taxation on the sale of the home and the liquidation of stock index fund (e.g., through withdrawals from a $401 \mathrm{k}$ when labor income is zero). The proceeds of these transactions, along with the individual's money market fund balance, are then used to purchases an annuity that provides a fixed level of consumption, $C^{R}=\frac{r W_{T}}{1-e^{-R r}}$, for the rest of the individual's life. ${ }^{8}$ The terminal utility, $U_{T}$, then becomes:

$$
U_{T}\left(W_{T}\right)=\int_{0}^{R} e^{-k x} U\left(C^{R}\right) d x=\frac{1-e^{-R k}}{k} * U\left(C^{R}\right)
$$

\footnotetext{
${ }^{8}$ The individual is assumed to rent upon retirement.
} 
Next, we consider the evolution of wealth over time. Let $\phi_{t}$ denote the proportion of wealth invested in the stock market, and $\eta_{t}$, denote the proportion of wealth invested in the house. In the base case the individual owns a particular house until retirement and the allocation to real estate $\eta_{t}=H_{t} / W_{t}$ is stochastic, but not under his or her control. It follows that $1-\phi_{t}-\eta_{t}$ is the proportion invested in the "money market fund". In general, this proportion will be negative, because real estate purchases are typically highly leveraged. Thus, the evolution of real after tax total wealth, $W_{t}$, is given by:

$$
\frac{d W}{W}=\phi \frac{d S}{S}+\eta \frac{d H}{H}+(1-\phi-\eta)(r(1-\tau)-i \tau) d t+\frac{(y(1-\tau)-C) d t}{W}
$$

where $\tau$ denotes the tax rate and $r$ is the real before-tax interest rate. Note that even though all assets, wealth, and income are in real terms, inflation affects the evolution of wealth $(-i \tau)$ because taxes are paid on nominal interest income from the money market fund. Equation (6) reflects our previously noted assumption that the individual is able to avoid taxation on home value and stock market appreciation.

The Bellman equation is:

$$
\underset{C, \phi}{\operatorname{Max}}\left[e^{-k t} U(C)+E(d V) / d t\right]=0
$$

Using Ito's Lemma we derive the following expression for the evolution of the value function:

$$
\begin{aligned}
d V= & V_{t} d t+V_{W} d W+\frac{1}{2} V_{W W}(d W)^{2}+V_{H} d H+\frac{1}{2} V_{H H}(d H)^{2}+V_{y} d y+\frac{1}{2} V_{y y}(d y)^{2}+ \\
& +V_{W H} d W d H+V_{y H} d y d H+V_{y W} d y d W
\end{aligned}
$$


Substituting into the Bellman Equation (7), taking expectations, and using $\eta_{t}=H_{t} / W_{t}$ we obtain:

$$
\begin{aligned}
0= & \max \left[e^{-k t} U(C)+V_{t}+\left(\frac{1}{2} \sigma_{S}^{2} \phi^{2} W^{2}+\frac{1}{2} \sigma_{H}^{2} H^{2}+\phi H W \sigma_{S H}\right) V_{W W}+\frac{1}{2} \sigma_{H}^{2} H^{2} V_{H H}+\right. \\
& +\frac{1}{2} V_{y y} y^{2} \sigma_{y}^{2}+V_{W H}\left(\phi H W \sigma_{S H}+\sigma_{H}^{2} H^{2}\right)+y H \sigma_{y H} V_{y H}+ \\
& \left.+V_{y W}\left(\phi W y \sigma_{y S}+H y \sigma_{y H}\right)\right) d t+V_{H} H \mu_{H}+V_{y} y \mu_{y}+ \\
& \left.+V_{W} W\left(\phi\left(\mu_{S}+r\right)+\mu_{H} \frac{H}{W}+\left(1-\phi-\frac{H}{W}\right)(r(1-\tau)-i t)\right)+V_{W}(y(1-\tau)-C)\right]
\end{aligned}
$$

Differentiating equation (9) with respect to $C$ and $\phi$ gives the following first-order conditions:

$$
\begin{gathered}
e^{-k t} U_{C}-V_{W}=0 \\
\sigma_{S}^{2} W V_{W W} \phi+\sigma_{S H} H V_{W W}+H \sigma_{S H} V_{W H}+V_{W}\left(\mu_{S}+(r+i) \tau\right)+\sigma_{y S} y V_{y W}=0
\end{gathered}
$$

The optimal controls are:

$$
\begin{gathered}
C^{*}=\left(e^{k t} V_{W}\right)^{-\frac{1}{\gamma}} \\
\phi^{*}=\frac{\sigma_{S H} H V_{W W}+H \sigma_{S H} V_{W H}+V_{W}\left(\mu_{S}+(r+i) \tau\right)+\sigma_{y S} y V_{y W}}{\sigma_{S}^{2} W V_{W W}}
\end{gathered}
$$

Substituting the optimal controls (12) and (13) into Equation (9) results in a partial differential equation for the value function. This optimization is subject to the following constraints: 


$$
\begin{aligned}
& \frac{1}{2} \phi W+(1-\lambda) H \leq W \text { for all } t \\
& V\left(W_{t}, H_{t}, y_{t}, t\right)=U_{T}\left(W_{T}\right)=\frac{1-e^{-R k}}{k} * U\left(C^{R}\right) \text { at } t=T \\
& \phi \geq 0 \text { for all } t
\end{aligned}
$$

where $\lambda$ denotes the maximum allowable loan-to-value ratio and investment in stocks is subject to $50 \%$ margin requirement. The first constraint simply states that the investment in stocks, at 50\% margin, plus the minimum home equity cannot exceed the total wealth of the individual. It should be noted that this constraint implies that a decline in home values may trigger a "margin call" where by the individual has to redeem part of his investment in the stock fund so that the maximum loan-to-value requirement is satisfied.

\subsection{Asset Allocation Benchmark Case}

In the benchmark case we separate the housing consumption decision from the real estate investment decision. Analytically we accomplish this by allowing the representative individual to sell a fractional interest in their home. In this way the individual can freely invest any non-negative proportion of their real total wealth into residential real estate. In both the base and benchmark cases, the individual has just purchased the house they live in for $H$. The individual lives in the house, but we now assume there is a market where fractional interests in a home can be sold.

In the base case the value of the individual's investment in housing is exogenously determined and we focus on the allocation of financial wealth. Here the investment in residential real estate is a choice variable. To adjust the actual to the desired level of investment in real estate the individual sells an interest in their house equal to $H-\eta W .{ }^{9}$ As with dividends when stocks are sold "short," the individual has to pay "rent" of $\delta$ per dollar of value that is sold, that is a partial rent of $\delta(H-\eta W)$.

It follows that in the unconstrained or benchmark case that evolution of wealth is given by: 


$$
\begin{aligned}
\frac{d W}{W}= & \phi \frac{d S}{S}+\eta \frac{d H}{H}+ \\
& +(1-\phi-\eta)(r(1-\tau)-i \tau) d t+\frac{(y(1-\tau)-C-\delta(H-\eta W)) d t}{W}
\end{aligned}
$$

The Bellman equation becomes:

$$
\begin{aligned}
0= & \max \left[e^{-k t} U(C)+V_{t}+\left(\frac{1}{2} \sigma_{S}^{2} \phi^{2} W^{2}+\frac{1}{2} \sigma_{H}^{2} \eta^{2} W^{2}+\phi \eta W^{2} \sigma_{S H}\right) V_{W W}+\frac{1}{2} \sigma_{H}^{2} H^{2} V_{H H}+\right. \\
& +\frac{1}{2} V_{y y} y^{2} \sigma_{y}^{2}+V_{W H}\left(\phi W H \sigma_{S H}+\eta W H \sigma_{H}^{2}\right)+y H \sigma_{y H} V_{y H}+ \\
& +V_{y W}\left(\phi W y \sigma_{y S}+\eta W y \sigma_{y H}\right)+V_{H} H \mu_{H}+V_{y} y \mu_{y}+ \\
& \left.+V_{W} W\left(\phi\left(\mu_{S}+r\right)+\eta \mu_{H}+(1-\phi-\eta)(r(1-\tau)-i t)\right)+V_{W}(y(1-\tau)-C-\delta(H-\eta W))\right]
\end{aligned}
$$

Differentiating equation (16) with respect to $C, \phi$ and $\eta$ gives the following firstorder conditions:

$$
\begin{gathered}
e^{-k t} U_{C}-V_{W}=0 \\
\sigma_{S}^{2} W V_{W W} \phi+\eta \sigma_{S H} W V_{W W}+\sigma_{S H} H V_{W H}+V_{W}\left(\mu_{S}+(r+i) \tau\right)+\sigma_{y S} y V_{y W}=0 \\
\eta W \sigma_{H}^{2} V_{W W}+\phi \sigma_{S H} W V_{W W}+\sigma_{H}^{2} H V_{W H}+V_{W}\left(\mu_{H}+\delta-r(1-\tau)+i \tau\right)+\sigma_{y H} y V_{y W}=0
\end{gathered}
$$

To simplify the expressions for the optimal controls, we adopt the following notation:

$$
\begin{aligned}
& a=\sigma_{S}^{2} W V_{W W} \\
& b=\sigma_{S H} W V_{W W} \\
& c=V_{W}\left(\mu_{S}+(r+i) \tau\right)+\sigma_{y S} y V_{y W}+\sigma_{S H} H V_{W H} \\
& d=\sigma_{S H} W V_{W W} \\
& f=\sigma_{H}^{2} W V_{W W} \\
& g=\sigma_{H}^{2} V_{W H}+V_{W}\left(\mu_{H}+\delta-r(1-\tau)+i \tau\right)+\sigma_{y H} y V_{y W}
\end{aligned}
$$

\footnotetext{
${ }^{9}$ Transactions costs would decrease the advantage of selling a fractional interest in the house and reduce the effect of the housing constraint.
} 
Equations (18) and (19) can then be expressed in matrix form as:

$$
\left(\begin{array}{ll}
a & b \\
d & f
\end{array}\right)\left(\begin{array}{l}
\phi \\
\eta
\end{array}\right)=\left(\begin{array}{l}
-c \\
-g
\end{array}\right)
$$

The optimal controls $C^{*}, \phi^{*}$ and $\eta^{*}$ are:

$$
\begin{aligned}
C^{*} & =\left(e^{k t} V_{W}\right)^{-\frac{1}{\gamma}} \\
\phi^{*} & =\frac{-c f+b g}{a f-b d} \\
\eta^{*} & =\frac{c d-a g}{a f-b d}
\end{aligned}
$$

The above optimization is subject to the following constraints:

$$
\begin{aligned}
& \frac{1}{2} \phi W+\eta W(1-\lambda) \leq W \text { for all } t \\
& V\left(W_{t}, H_{t}, y_{t} t\right)=U_{T}\left(W_{T}\right)=\frac{1-e^{-R k}}{k} * U\left(C^{R}\right) \text { at } t=T \\
& \phi \geq 0 \text { for all } t \\
& \eta \geq 0 \text { for all } t
\end{aligned}
$$

\subsection{Numerical Implementation and Data}

The effect of the homeownership constraint on asset allocation and postretirement wealth would be expected to depend upon the individual's preferences and the investment opportunity set (e.g., risk and rates of returns). In our analysis we have chosen default values for all parameters that we think are close to reality and reasonably represent the choices faced by a typical home owner. Table 1 specifies the parameters of the model and the default values assumed in computing the subsequent figures. Table 2 lists the technical assumptions required for the finite difference solution methodology employed to solve both the constrained (base) and unconstrained (benchmark) cases. 
The numerical implementation utilizes an explicit finite difference approximation to solve differential equations (9) and (16) subject to the respective optimal controls and boundary conditions described above. Unlike most continuous time asset allocation models, we cannot exclude wealth from our model. In fact, the relationship between wealth and home value is a crucial element of our investigation. However, including wealth in the solution poses a number of computational difficulties. First, the typical boundary conditions of setting the first and second derivatives to zero or constants cannot be used in our setting because some of them enter the denominator of the expressions for the optimal controls. Instead, we set the ratio of the first and second derivatives, $V_{W} / W V_{W W}$, to a constant at the boundary. This provides for very smooth and stable solutions.

Furthermore, the higher order derivatives of the utility function we employ are non-zero and change substantially over the range of total wealth we consider. For instance, the third derivative is very high in absolute value for low levels of wealth, and is numerically indistinguishable from zero for high levels of wealth. The error of the first or second order numerical derivatives is sensitive to the higher order derivatives, which introduces a consistent bias in the optimization purely based on the numerical approximation. To remedy this potentially serious problem we employ an exponentially variable grid in $W$. For low levels of wealth, the grid is very dense, which reduces the numerical error in the first and second derivatives. For larger levels of wealth, the grid is sparse, which allows for numerically tractable computation of the derivatives. Employing a variable grid is equivalent to a transformation in the state variables and the utility function. To the extent that such transformation could potentially introduce further numerical errors and would make presentation of the results more difficult, we choose the variable grid approach.

\subsection{The Effect of the Home Ownership Constraint}

The purpose of this paper is to evaluate the effect of the homeownership constraint on asset allocation and terminal wealth. In this way we can estimate the utility loss associated with the inability to separate the decision as to how many housing 
services to consume from the decision as to how much to investment in residential real estate.

\subsection{Home Ownership and Total Expected Utility}

To picture the effect of the homeownership constraint, Figure 1 depicts the evolution of the optimal controls and state variables through time (i.e., over the 20 year time horizon to retirement) assuming stocks and real estate appreciate at their expected rate of return. The starting point of the solution depicted in this figure is defined by the default parameters presented in Table 1.

Panel A depicts the allocation of total wealth to stocks and housing. The allocation to the money market fund is the complement of the sum of the allocations to stocks and housing. The vertical axis is the proportion of total wealth allocated to each asset. Initially, the allocation to stocks and real estate exceeds one and involves substantial borrowing (e.g., a negative allocation to the money market). This implies that initially in the base case it is optimal for the representative individual to borrow almost 3 times their net wealth. Since the allocation to real estate is constrained, the evolution of $\mathrm{H} / \mathrm{W}$ only reflects the growth of home value and wealth through time. The evolution of the allocation to stocks reflects the constraint on total investment in the stock index fund through year 12, after which the optimal allocation drops as retirement approaches.

Panel B depicts the optimal asset allocation in the benchmark case. The allocation to real estate is substantially lower relative to the base case at the beginning, and slightly larger towards the end. The allocation to stocks is driven by the total investment constrained until year 13, after which it starts to drop as retirement approaches. Panels $\mathrm{C}$ and $\mathrm{D}$ depict the evolutions of consumption and total wealth in the two cases. These evolutions are very similar because, while real estate has lower expected return, it can be purchased with higher leverage. In terms of expected return, this makes investment in stocks and in highly levered real estate approximately equal.

While the consumption and the evolution of total wealth are very similar in the two cases, the allocations to the assets are very different. Under the base case, the allocations change substantially over the time horizon. On average, the allocations in the benchmark case are less extreme and more consistent through time. Furthermore, the 
effect of the home ownership constraint is largest at the beginning, i.e., for young households who have little net worth relative to current income. As individuals accumulate wealth, the home ownership constraint becomes less binding and the asset allocations in the two cases become very similar.

These differences imply that the expected volatility of the total portfolio in the two cases is very different. Since the asset allocation is far more extreme in the base case, we would expect that the volatility of wealth would be higher. This suggests that the total expected utility in the base case is substantially lower. To verify this intuition, Figure 2 depicts the required compensation, as a percent of total wealth, for having to hold a pre-determined level of real estate. To construct this figure, we find the wealth levels that provide the same total utility in the two cases. We then report the percent difference in wealth that provides the same total utility.

As expected, the base case has lower total utility for all levels of wealth. For parameter values reported in Table 1, (i.e., $H=3.2, W=1.2$ ), this compensation is approximately $6 \%$ of total wealth, including equity in the house. If the initial allocation is more balanced and closer or equal to the allocation in the benchmark case (e.g., $H=1.5$, $W=1.5$ ), the required compensation still exceeds $1 \%$ of total wealth because future adjustments are not possible in the base case. As the initial holding of real estate gets larger while the total wealth remains small (e.g., $H=4, W=1.2$ ), the required compensation increases to as much as $10 \%$. On the other extreme, if the allocation to the house is substantially lower then the total wealth (e.g., $W=6, H=1.5$ ), the required compensation starts to increase slightly, but for a different reason: the investment in the house is below optimal.

While Figure 2 is informative, it does not account for the impact of income on the required compensation. Figure 3 depicts the required compensation as a function of property values and starting income. For the initial case (i.e., $H=3.2, y=1$ ), this compensation is approximately $6 \%$ of total wealth which is the same as in Figure 2 . As expected, higher values of $H$ increase the required compensation. Somewhat surprisingly, higher income results in higher compensation. Higher income makes investing in stocks even more attractive. Having to hold a large fraction of wealth in real estate decreases the ability to invest in stocks due to the minimum equity requirement. 
This is why compensation increases with income. This effect is largest if the value of the house is large, and can exceed $15 \%$ of total wealth over the range of real estate values and income considered.

The main finding reported in Figures 2 and 3 is that even though consumption is very similar in both base and a benchmark cases, the total utility is substantially lower for the base case. In other words, a forced investment in real estate is utility reducing. The monetary equivalent of this reduction in total utility is between 1 and $15 \%$ over the range of state variables examined.

\subsection{Asset Allocation and Consumption}

In what follows we compare the asset allocation and consumption decisions in the base and benchmark cases. Figure 4 depicts the asset allocations and consumption in the two cases and the difference between them. Panels A through D depict the allocations and consumption in the base case. Panels $\mathrm{E}$ through $\mathrm{H}$ depict the allocations and consumption in the benchmark case, and Panels I through L depict the allocation in the base case minus the allocation in the benchmark case for each asset or consumption.

The allocation to stocks depicted in Panels A and E exhibits an interesting pattern. For low levels of wealth, the allocation is constrained by the total investment limit. For higher levels of wealth, the allocation is not constrained. Unlike Merton's (1977) continuous time model, the unconstrained optimal allocation to stocks is not constant because of two reasons. First, human capital is not included in total wealth yet we include the income from human capital in the optimization. This is particularly important for low levels of total wealth (excluding non-human capital). Individuals in this situation have high income, but low net worth. According to our model, it is optimal for such individuals to invest as much as possible in the stock fund.

The second reason for the dependence of the allocation to stock on the state variables in the benchmark case is that the value of real estate, $H$, determines the "rent" payments the owner needs to make if they sell a fractional interest in their home. Higher real estate values result in higher rent, which, in turn, reduces the allocation of wealth to stocks. 
This effect is also evident in the allocation to real estate in the two cases. By construction, the allocation to real estate in the base case (Panel B) is directly proportional to the value of the house, $H$. The allocation in the benchmark case (Panel F) can be adjusted, however. Nonetheless, the individual chooses to invest higher proportion of total wealth into housing in face of high real estate values. This choice reflects the hedging benefits of real estate ownership as discussed by Sinai and Souleles (2002). We will see below that this hedging demand for real estate disappears as retirement approaches.

The investment in the money market fund also exhibits an interesting pattern. Intuitively, lower levels of wealth result in higher borrowing in both cases due to the inability to borrow against human capital. Notice, however, that for low levels of wealth borrowing is substantially more extreme in the base case. The kink shown in both cases reflects the areas where the total borrowing constraint is binding. For wealth levels above the kink, the total borrowing constraint is not binding and all allocations are optimal.

Finally, for all levels of total wealth, $W$, consumption declines marginally for higher levels of $H$ in both cases. For the base case, this effect is intuitive because higher forced investment in real estate increases the marginal value of wealth, which, in turn, reduces the optimal consumption level. For the benchmark case, higher value of real estate increases the "rent" payments required if a portion of the house is sold, which, in turn, induces the individual to consume less and save more.

Figure 5 depicts the optimal allocations and consumption in the two cases and the difference between them as a function of income, $y$, and house value, $H$. Panels A through D depict the allocations and consumption in the base case. Panels E through $\mathrm{H}$ depict the allocations and consumption in the benchmark case, and Panels I through L depict the allocation in the base case minus the allocation in the benchmark case for each asset or consumption. The allocations in the base case are independent of income because the total borrowing constraint is binding and the holding of real estate cannot be changed. Higher income makes investing in stocks more attractive, which is reflected in the allocations of the benchmark case. The allocation to real estate decreases with income in the benchmark case because stocks are more attractive for higher income and 
the total borrowing constraint is still binding. In other words, individuals reduce their real estate holdings to free up funds to invest in the stock market. This is a strong result considering that by assumption real estate can be purchased at a substantially higher leverage then stocks.

The level of consumption (Panels D and $\mathrm{H}$ ) is, as would be expected, increasing in income. Consistent with the above analysis of the investment in real estate, consumption falls for higher real estate values. Notice that for all levels of income and house values consumption in the benchmark case is slightly higher reflecting the anticipation of higher returns and lower risk due to better asset allocation.

To reinforce the message of the above figures, Table 3 reports the exact required compensation and allocation for several important situations. The first line depicts the initial case using the parameters of Table 1. The following three lines hold real estate and income constant and allow wealth to increase. Not surprisingly, higher wealth levels are associated with lower required compensation. This is another way of saying that the home ownership constraint is less binding for wealthier individuals. The allocation to real estate in the base case is by construction falling for higher levels of total wealth. Notice that the allocation to real estate in the benchmark case is also falling for higher levels of wealth. This suggests that a portion of the demand for real estate in the unconstrained case is driven by the desire to hedge against future increases of real estate values as discussed above.

Another interesting result is that the allocation to real estate is actually slightly higher in the benchmark case for extremely high levels of wealth. This suggests that the home ownership constraint may be limiting not only because it forces individuals to hold too much real estate, but, in some circumstances, because it forces them to hold too little. This is consistent with the pattern of required compensation reported in Figure 2.

The next three rows of Table 3 hold wealth and income constant but allow home values to increase. Not surprisingly, higher real estate values result in higher required compensation. Furthermore, the difference between the asset allocations in the base and benchmark cases increases. Interestingly, the allocation to real estate in the benchmark case increases with home prices even though the individual can freely reduce their 
investment in real estate. This is due to the hedging demand for housing discussed above.

The final three rows hold total wealth and real estate constant and allow income to grow. Interestingly, higher levels of income require higher compensation. As discussed above, this is due to the increased impact of the total borrowing constraint.

\subsection{Evolution of Asset Allocation through Time}

Most of the analysis so far was focused on the optimal allocations at time zero. The one exception was the evolutions of asset allocations, consumption, and wealth reported in Figure 1, but they are based on a single starting point. In what follows, we examine the evolution of the asset allocation through time for the entire state space under consideration.

Figure 6 depicts the allocation to stocks in the base and benchmark cases and the difference between them through time. We report the allocations for time zero and years $5,10,15$, and 19.9 (i.e., one month to retirement). The first row is identical to the allocations to stocks in Figure 4. As time progresses, the total borrowing constraint becomes binding in fewer and fewer situations. With very little time left to retirement, the benchmark case is entirely unconstrained and the optimal allocation to stocks is virtually independent of the state variables (notice the scale on the figure). This is essentially a static optimization until retirement. Notice that the optimal allocation to stocks falls as the time of retirement approaches.

Figure 7 depicts the evolution of the real estate allocation. The first row is identical to the allocations to real estate in Figure 4. By construction, the allocation to real estate in the base case does not change over time. The allocation in the benchmark case substantially drops over time. This is consistent with the fewer years of income remaining. It also allows the total borrowing constraint to become less binding with time.

Finally, Figure 8 depicts the evolution of the money market allocation. The kink in all figures reflects the total borrowing constraint. For levels of wealth below the kink the total borrowing constraint is binding, and for levels above the kink it is not. The allocation to bonds in the base case marginally goes down in time. The allocation to 
bonds in the benchmark case substantially drops through time, especially in the last few years.

\subsection{Conclusion}

Buying a home is a lumpy investment that places a constraint on the owner's asset allocation decisions. In this paper we analyze the impact of this constraint on a representative individual's consumption, welfare and post retirement wealth. We consider a representative individual who has irreversibly chosen the home to live in until retirement. We investigate his or her optimal asset allocation decisions when subject to a homeownership constraint. Next, we consider the same individual's asset allocation decisions when they have the ability to sell, without cost, a fractional interest in their home. By comparing the asset allocation decisions and terminal wealth in these two cases, we estimate the differences in post-retirement wealth and the welfare gains potentially realizable if individuals' asset allocation were not subject to the home ownership constraint.

For realistic parameter values we find that a homeownership constraint has a relatively large effect on the representative individual's asset allocation. Specifically the individual invests a larger than optimal fraction of his or her wealth in a home when investments in homes are lumpy and constrained. We conclude that home owners would require a $6 \%$ increase in total net worth to achieve the same utility level as an individual not facing the asset allocation constraint. As would be expected, the required compensation and the differences in asset allocation between the two cases diminish with time.

Somewhat surprisingly we find that the evolution of wealth and consumption, if all assets receive their expected rate of return, is similar in the two cases. Even though real estate tends to have lower total return then stocks, it can be purchased with higher leverage that can potentially increase the expected return on investment. In a stochastic environment, however, the evolution of wealth and consumption can be very different in the two cases, as reflected in the total loss of utility due to the home ownership constraint.

We further show that demand for real estate has a small but important hedging component. Specifically, individuals invest more in real estate then predicted by the risk- 
return characteristics of the pure investment asset. The desire to hedge against future increases in rent payments generates this additional demand. Nonetheless, for reasonable parameter values, the total investment in real estate is substantially lower if the individual can freely choose their asset allocation. 


\section{REFFERENCES}

Bertaut, C. and M. Haliassos. 1997. Precautinary Portfolio Behavior from a Life-Cycle Perspective. Journal of Economic Dynamics and Control. 21:1511-1542

Brennan, M., E. Schwartz and R. Lagnado. 1997. Strategic Asset Allocation. Journal of Economic Dynamics and Control. 21:1377-1403

Cauley, S. and A. Pavlov. 2002. Rational Delays: The Case of Real Estate. Journal of Real Estate Finance and Economics. 24(1/2):143-165.

Cocco, J. 1999. Portfolio Choice in the Presence of Illiquid Durable Consumption Goods and Nontradable Income. Working Paper.

Cocco, J. 2000. Hedging House Price Risk with Incomplete Markets. Working Paper.

Cocco, J, F. Gomes and P. Maenhout. 1999. Consumption and Portfolio Choice over the Life-Cycle. Working Paper.

Flavin, M. and T. Yamashita. 2002. Owner-occupied housing and the composition of the household portfolio. The American Economic Review. 92:345-363.

Glaeser,E and J. Shapiro. 2002. The Benefits of the Home mortgage Interest Deduction. NBER Working Paper, No. 9284

Goetzmann, W. 1993. The Single Family Home in the Investment Portfolio. Journal of Real Estate Finance and Economics. 6(3):201-222.

Goetzmann. W. and R. Ibbotson. 1990. The Performance of Real Estate as an Asset Class. Journal of Applied Corporate Finance. 3(1): 65-76

Grossman, S. and G. Laroque. 1991. Asset Pricing and Optimal Protfolio Choice in the Presence of Illiquid Durable Consumption Goods. Econometrica. 58:25-51.

Guiso, L., T. Jappelli, and D. Terlizzesse. 1996. Income Risk, Borrowing Constraints and Portfolio Choice. The American Economic Review. 86:158-172

Heaton, J. and D. Lucas. 1999. Market Frictions, Saving Behavior and Portfolio Choice. Macroeconomic Dynamics. 1:76-101

Merton, R. 1971. Optimum Consumption and Portfolio Rules in Continuous Time Model. Journal of Economic Theory. 3:373-413

Murphy, K. and F. Welch. 1990. Empirical Age-Earnings Profiles. Journal of Labor Economics. 8:202-229.

Pavlov, A. 2000. Space Varying Regression Coefficients: A Semi-Parametric Approach Applied to Real Estate Markets. Real Estate Economics. 28.2: 249-283.

Pavlov, A. 2001. Competing Risks of Mortgage Terminations: Who Refinances, Who Moves, and Who Defaults? Journal of Real Estate Finance and Economics. 23(2):185-211

Pavlov, A. and S. Wachter. 2002. The Option Value of Non-recourse Lending and Inflated Asset Prices. Working Paper 
Poterba, J. and A. Samwick. 1997. Household Portfolio Allocation Over the Life Cycle. NBER Working Paper, No. 6185

Ross. S. and R. Zisler. 1991. Risk and Return in Real Estate. Journal of Real Estate Finance and Economics. 4(2):175-190.

Sinai, T. and N. Souleles. 2003. Owner-occupied housing as a Hedge Against Rent Risk. NBER Working Paper, No. 9462 
Figure 1: Evolution of Asset Allocation, Consumption and Wealth

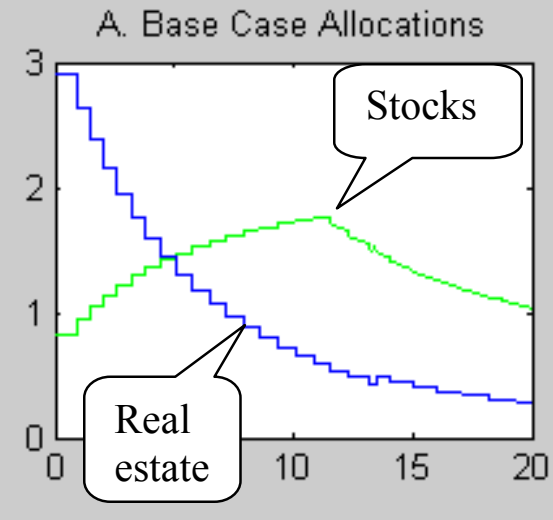

C. Consumption

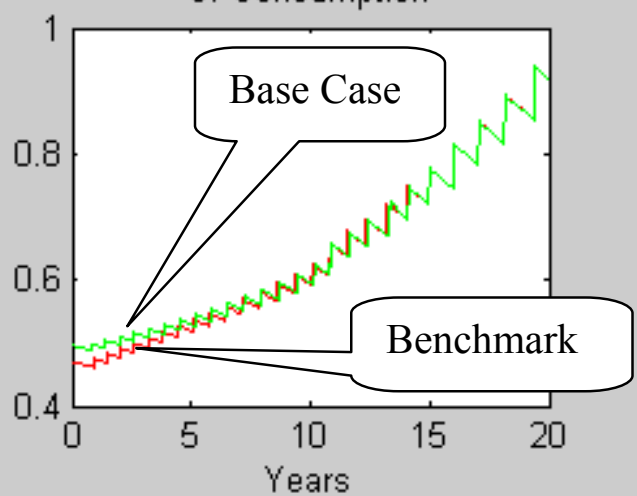

B. Benchmark Allocations

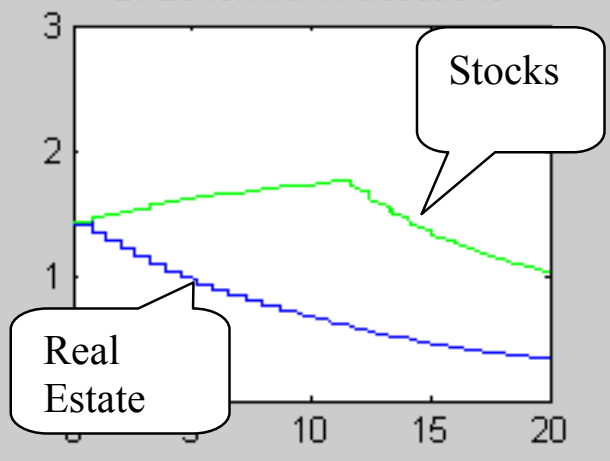

D. Evolutoin of wealth

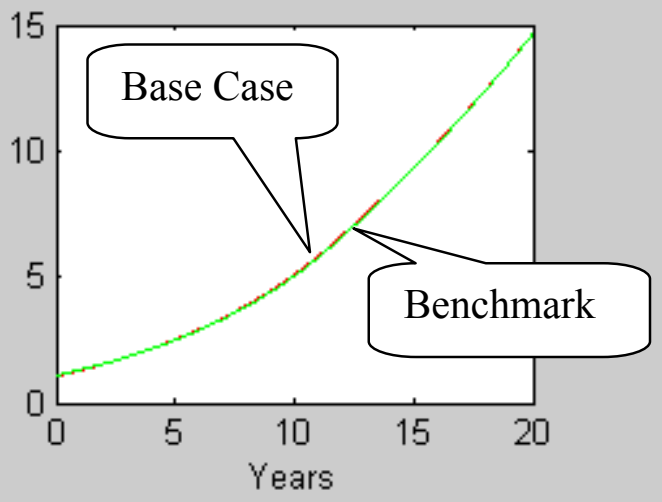

Figure 1 depicts the evolution of asset allocations, consumption, and wealth in the base and benchmark cases for a solution using the starting values of Table 1 and assuming all returns equal their expectation. Some figures are not smooth because the solution jumps through the grid lines of the finite difference method as wealth is accumulated. Panel A depicts the base case allocations to stocks and real estate. Since the allocation to real estate is constrained at $\mathrm{H} / \mathrm{W}$, it's evolution only reflects the growth of wealth through time. The evolution of the allocation to stocks reflects the constraint on total allocation through year 12, after which it optimally drops as retirement approaches. Panel B depicts the allocation to stocks and real estate in the benchmark case. The allocation to real estate is substantially lower at the beginning, and slightly larger towards the end. The allocation to stocks is driven by the total investment constrained until year 13, after which it starts to drop as retirement approaches. Panels C and D depict the evolutions of consumption and total wealth in the two cases. These evolutions are very similar because, while real estate has lower expected return, it can be purchased with higher leverage. In terms of expectation, this makes investment in stocks and in highly levered real estate approximately equal. 
Figure 2: Compensation for the Constraint

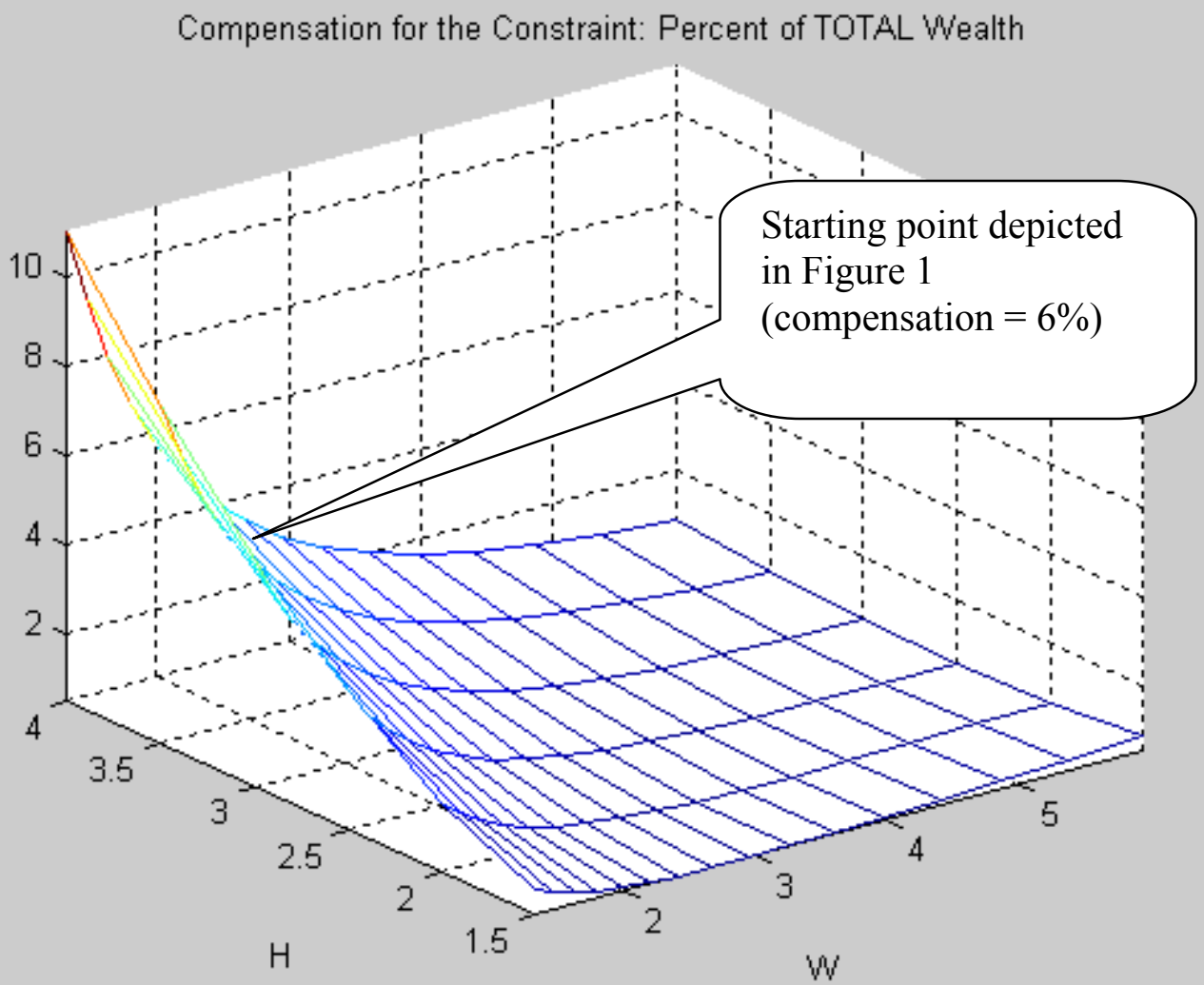

Figure 2 depicts the required compensation for having to hold a pre-determined level of real estate investment. The $\mathrm{x}$-axis depicts total wealth, $W$, which includes equity in the house, the $y$-axis depicts the value of the home, $H$, and the vertical axis depicts the required compensation as a percent of total wealth, $W$. For the base case (i.e., $H=3.2, W$ $=1.2, y=1)$, this compensation is approximately $6 \%$ of total wealth, including equity in the house. If the initial allocation is more balanced and closer or equal to the allocation in the unconstrained case (e.g., $H=2, W=2, y=1$ ), the required compensation still exceeds $1 \%$ of total wealth. As the initial holding of real estate gets larger while the total wealth remains small (e.g., $H=4, W=1.2, y=1$ ), the required compensation increases to as much as $10 \%$. On the other extreme, if the allocation to the house is substantially lower then the total wealth (e.g., $W=6, H=1.5, y=1$ ), the required compensation starts to increase but for a different reason: the investment in the house is below optimal. 
Figure 3: Compensation for the Constraint and Income

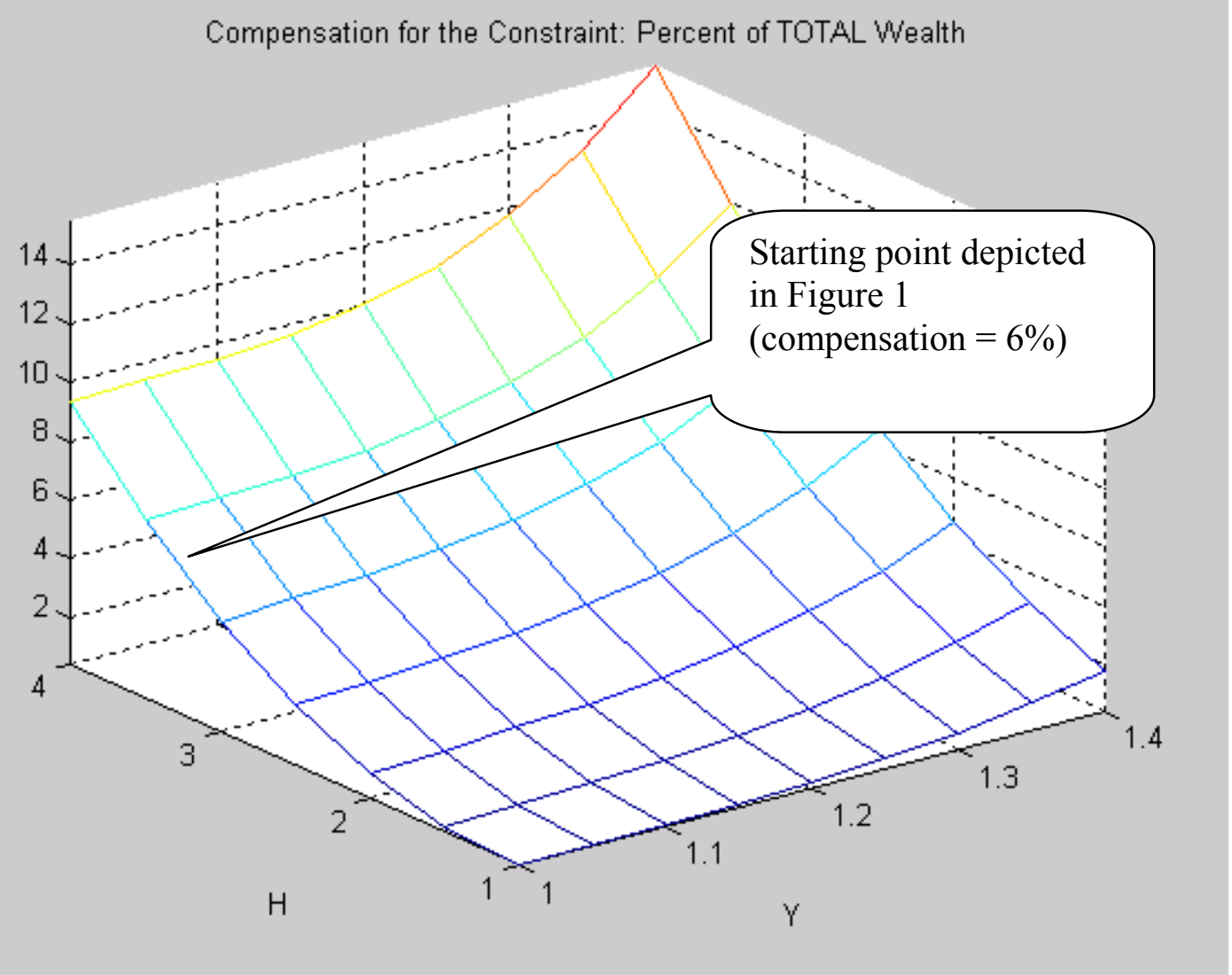

Figure 3 depicts the required compensation for having to hold a pre-determined level of real estate investment. The $\mathrm{x}$-axis depicts income, $y$, the $\mathrm{y}$-axis depicts the value of the home, $H$, and the vertical axis depicts the required compensation as a percent of total wealth, $W$. For the base case (i.e., $W=1.2, H=3.2, y=1$ ), this compensation is approximately $6 \%$ of total wealth, including equity in the house. As expected, higher values of $H$ increase the required compensation. Somewhat surprisingly, higher income results in higher compensation. Higher income makes investing in stocks even more attractive. Having to hold a large real estate property decreases the ability to invest in stocks due to the minimum equity requirement. This is why compensation increases with income. This effect is largest if the value of the house is large, and can exceed $15 \%$ of total wealth over the range of real estate values and income considered. 
Figure 4: Optimal Allocations and Consumption

A. Allocation to stocks: Base Case E. Allocation to stocks: Benchmark I. Allocation to stocks: difference
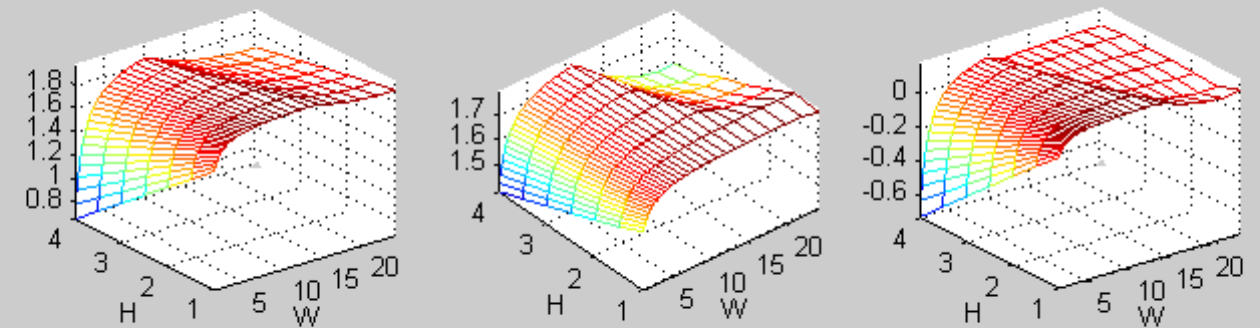

B. Allocation to house: Base Case F. Allocation to house: Benchmark

J. Allocation to house: difference
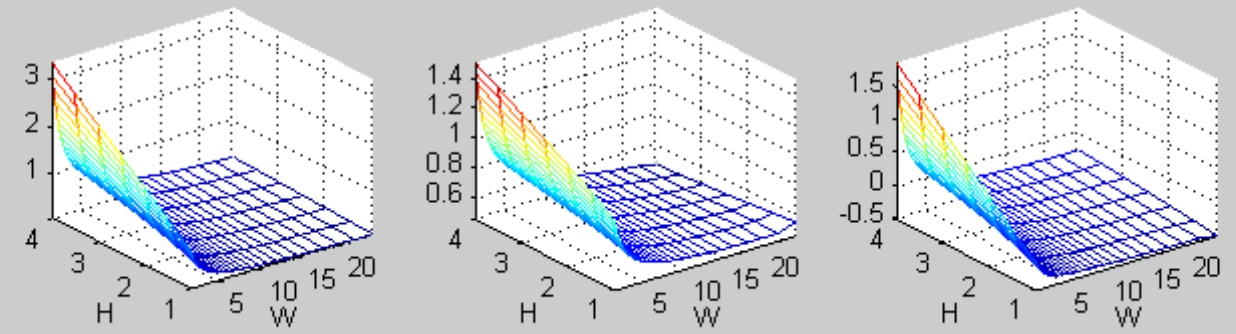

C. Allocation to bonds: Base Case G. Allocation to bonds: Benchmark

K. Allocation to bonds: difference
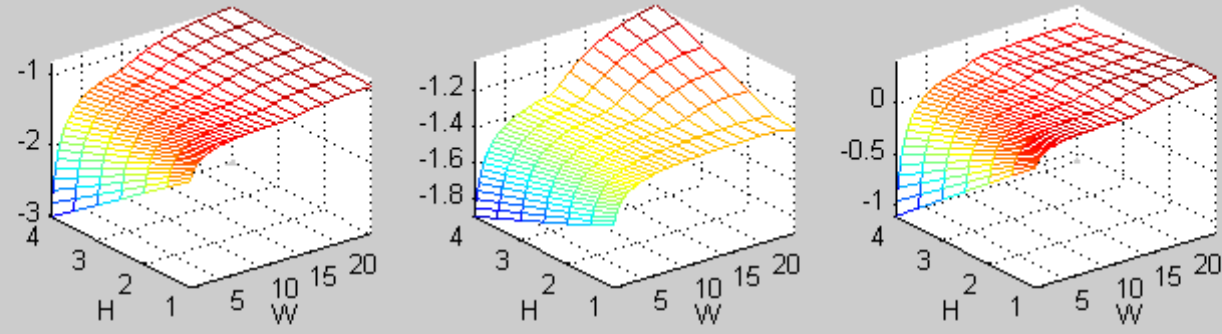

D. Consumption: Base Case

H. Consumption: Benchmark

L. Consumption: difference
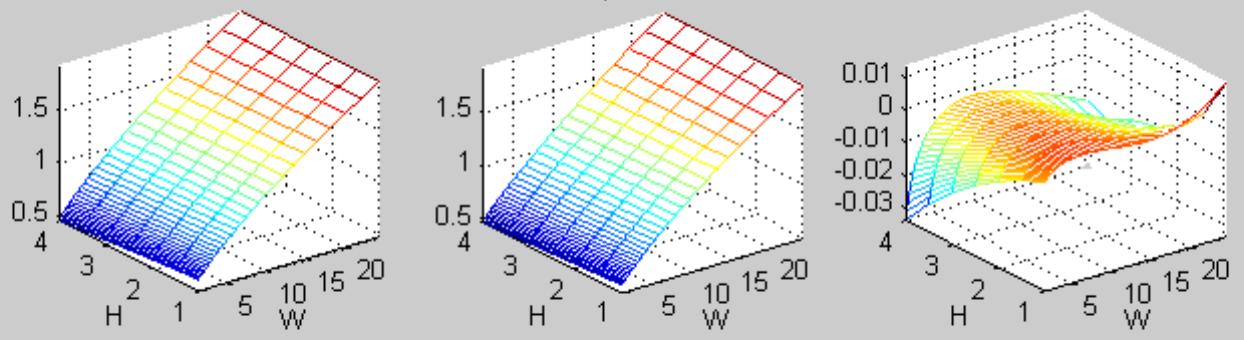

Figure 4 depicts the optimal allocations and consumption in the two cases and the difference between them as a function of total wealth, $W$, and house value, $H$, for a level of income of 1. Panels A through D depict the allocations and consumption in the base case. Panels $\mathrm{E}$ through $\mathrm{H}$ depict the allocations and consumption in the benchmark case, and Panels I through L depict the allocation in the base case minus the allocation in the benchmark case for each asset or consumption. The x-axis depicts the total wealth, $W$, and the $y$-axis depicts the value of the home, $H$. 
Figure 5: Optimal Allocations and Income
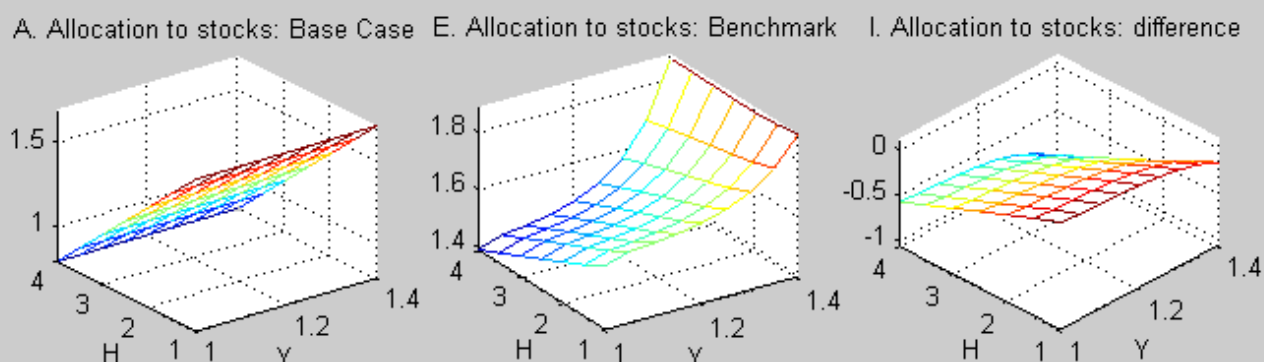

B. Allocation to house: Base Case

F. Allocation to house: Benchmark

J. Allocation to house: difference
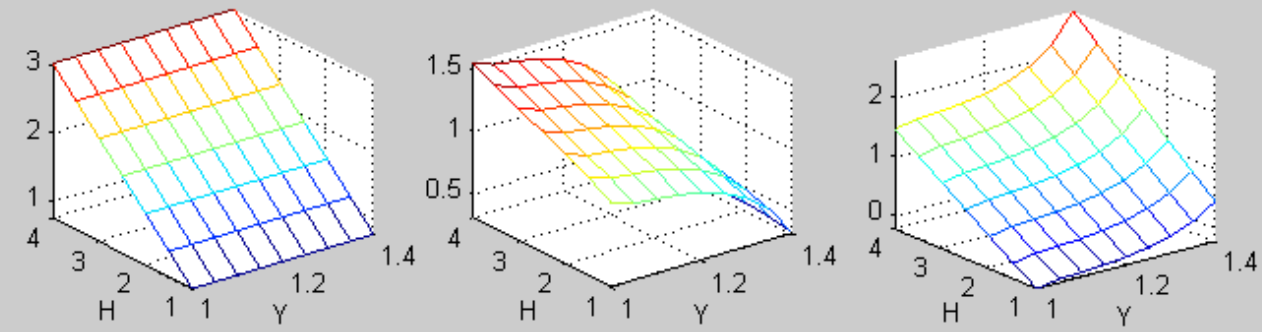

C. Allocation to bonds: Base Case

G. Allocation to bonds: Benchmark

K. Allocation to bonds: difference
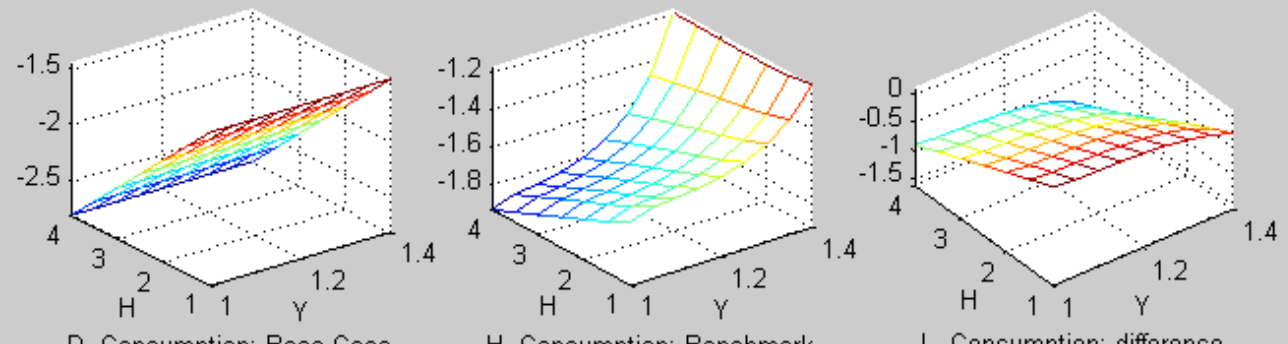

D. Consumption: Base Case

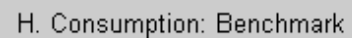

L. Consumption: difference
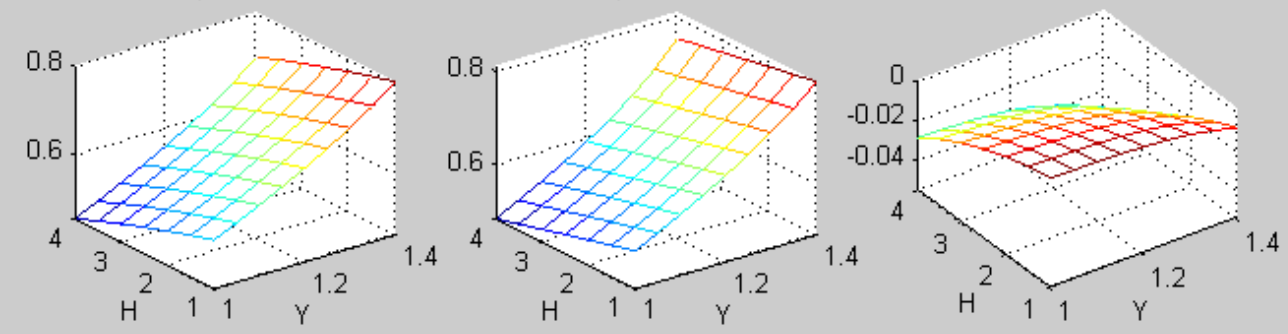

Figure 5 depicts the optimal allocations and consumption in the two cases and the difference between them as a function of income, $y$, and house value, $H$, for a constant level of wealth of 1.2. Panels A through D depict the allocations and consumption in the base case. Panels $\mathrm{E}$ through $\mathrm{H}$ depict the allocations and consumption in the benchmark case, and Panels I through L depict the allocation in the base case minus the allocation in the benchmark case for each asset or consumption. The $\mathrm{x}$-axis depicts the current income, $y$, and the y-axis depicts the value of the home, $H$. The allocations in the base case are independent of income because the total borrowing constraint is binding and the holding of real estate cannot be changed. 
Figure 6: Evolution of the Allocations to Stocks

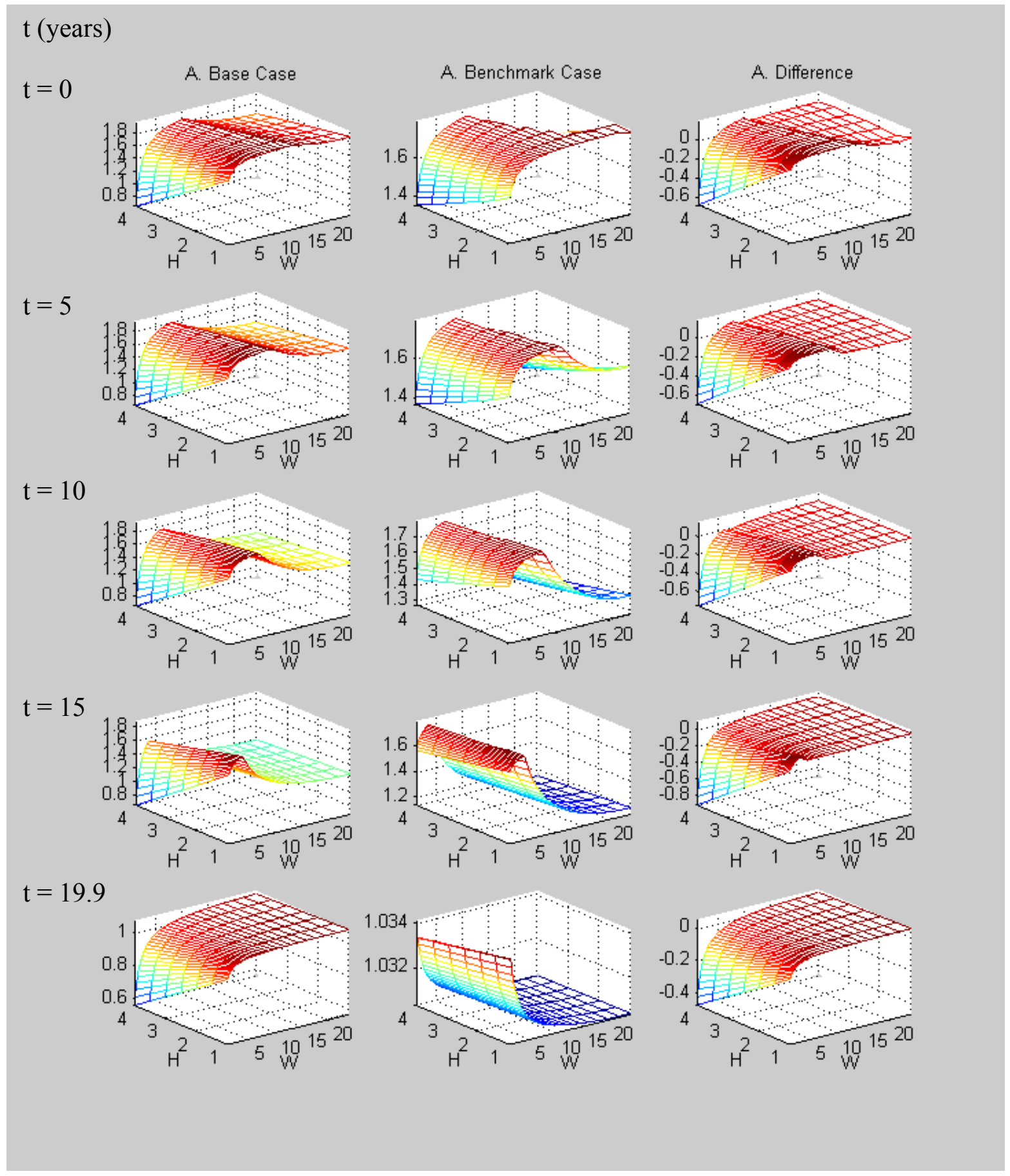

Figure 6 depicts the evolution of the allocation to stocks in the two cases for years 0,5 , 10,15 , and 19.9, i.e., one month to retirement. The first row is identical to the allocations to stocks in Figure 4. As time progresses, the total borrowing constraint becomes binding in fewer and fewer situations. With 1 year left to retirement, the benchmark case is entirely unconstrained. 
Figure 7: Evolution of the Allocations to Real Estate

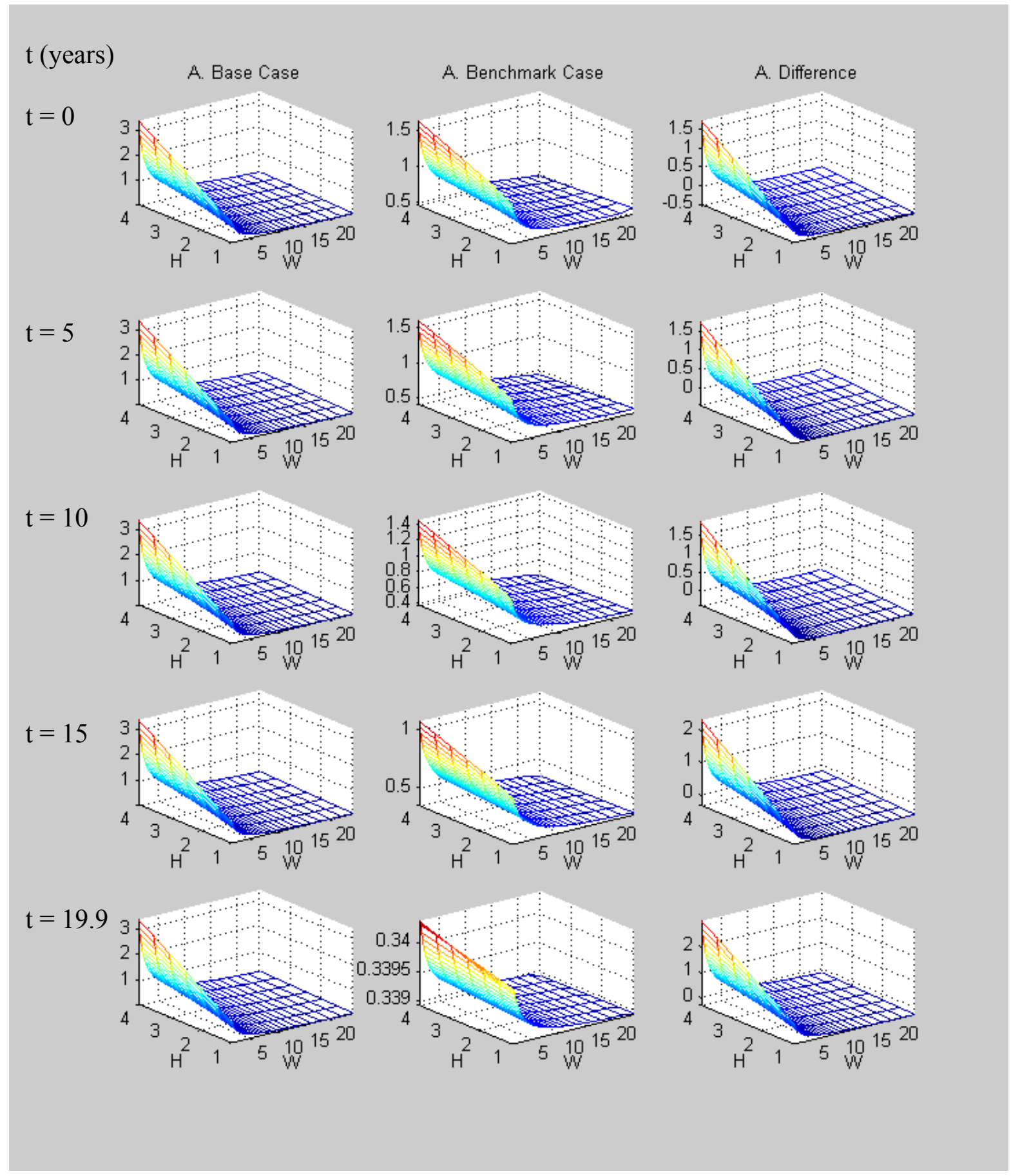

Figure 7 depicts the evolution of the allocation to real estate in the two cases for years 0 , $5,10,15$, and 19.9, i.e., one month to retirement. The first row is identical to the allocations to real estate in Figure 4. By construction, the allocation to real estate in the base case does not change over time. The allocation in the unconstrained case substantially drops over time. 
Figure 8: Evolution of the Allocations to Bonds

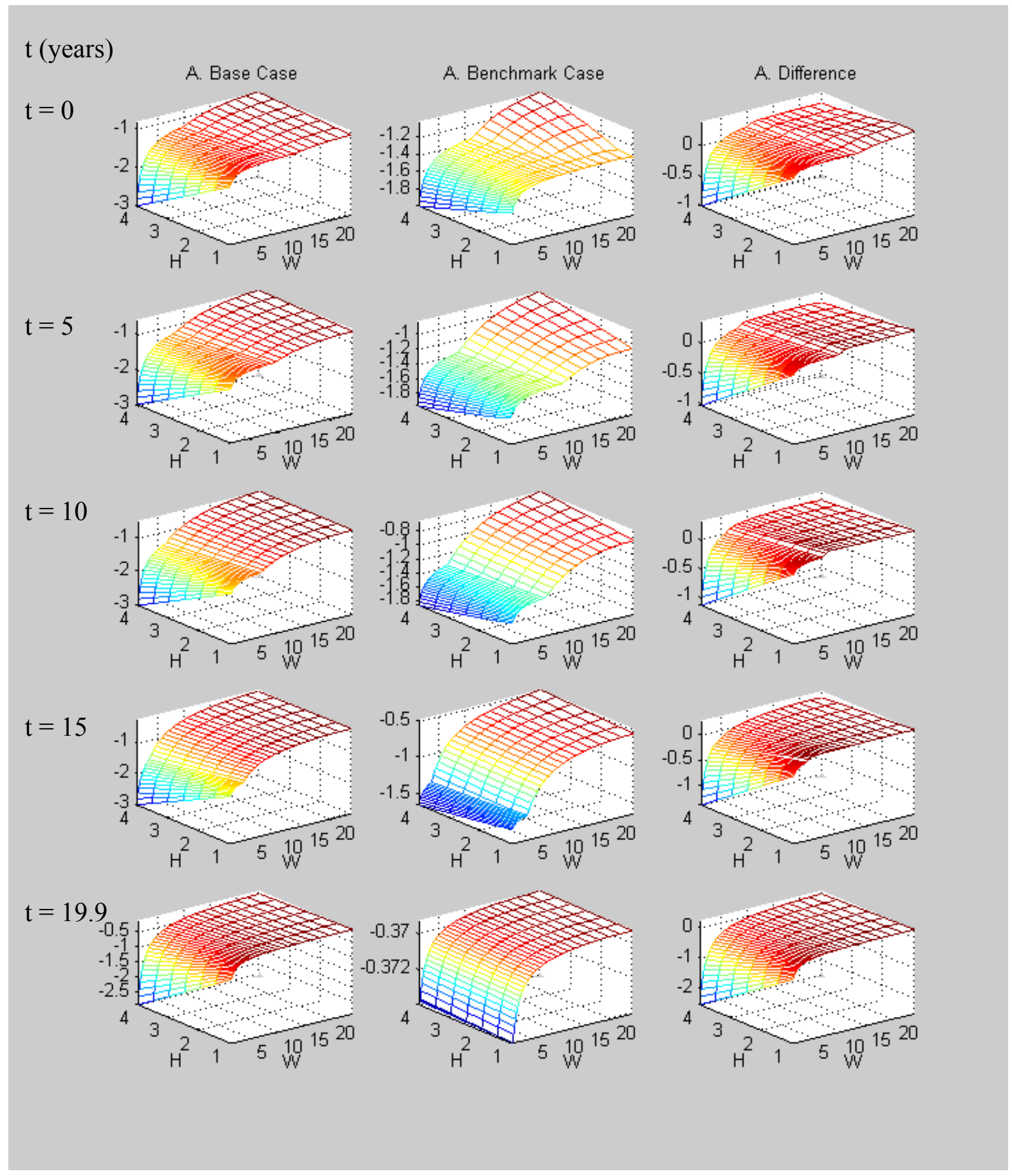

Figure 8 depicts the evolution of the allocation to bonds in the two cases for years 0,5 , 10,15 , and 19.9, i.e., one month to retirement. The kink in all figures reflects the total borrowing constraint. For levels of wealth below the kink the total borrowing constraint is binding, and for levels above the kink it is not. The allocation to bonds in the base case marginally goes down in time. The allocation to bonds in the benchmark case substantially drops through time, especially in the last few years. 

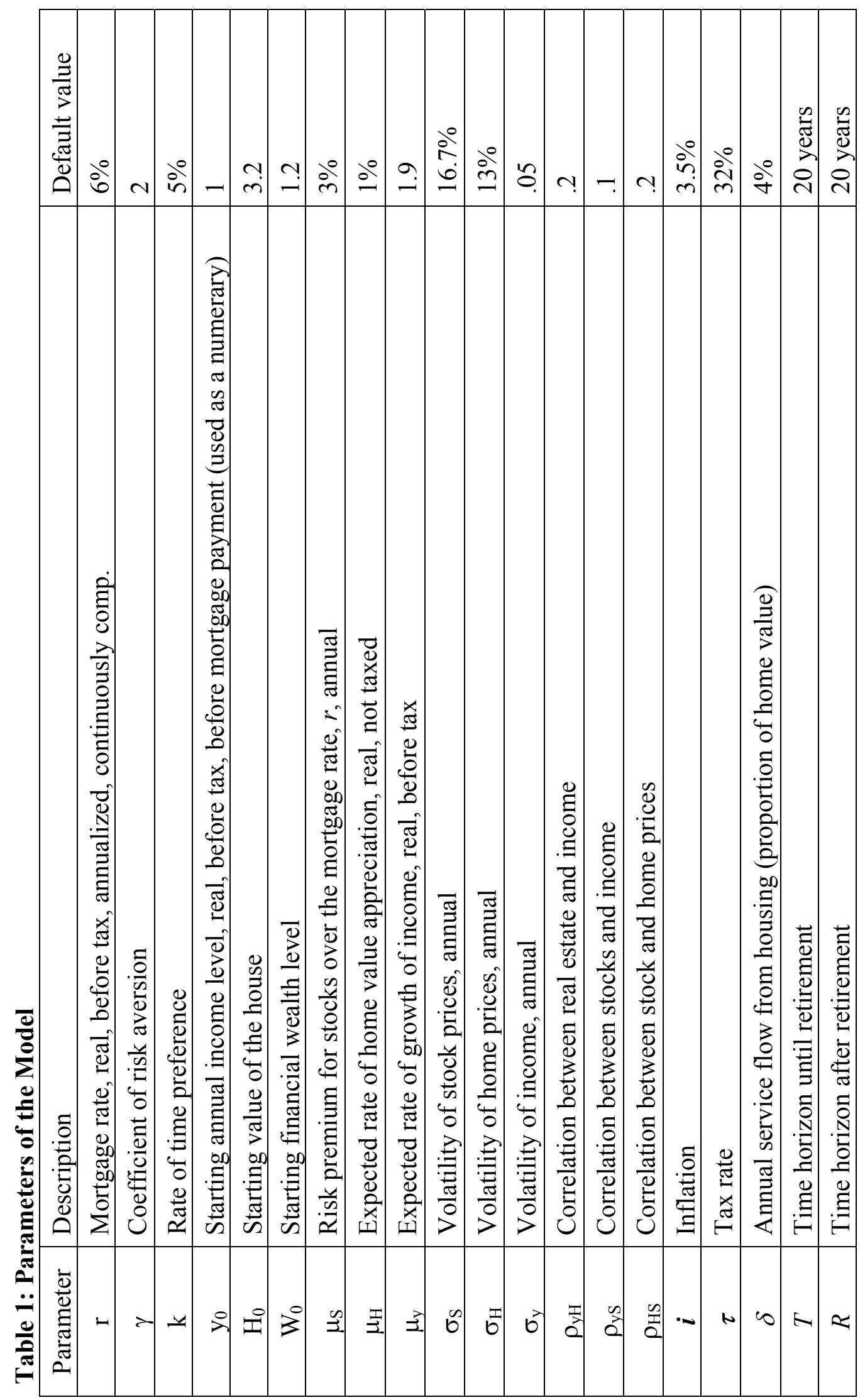


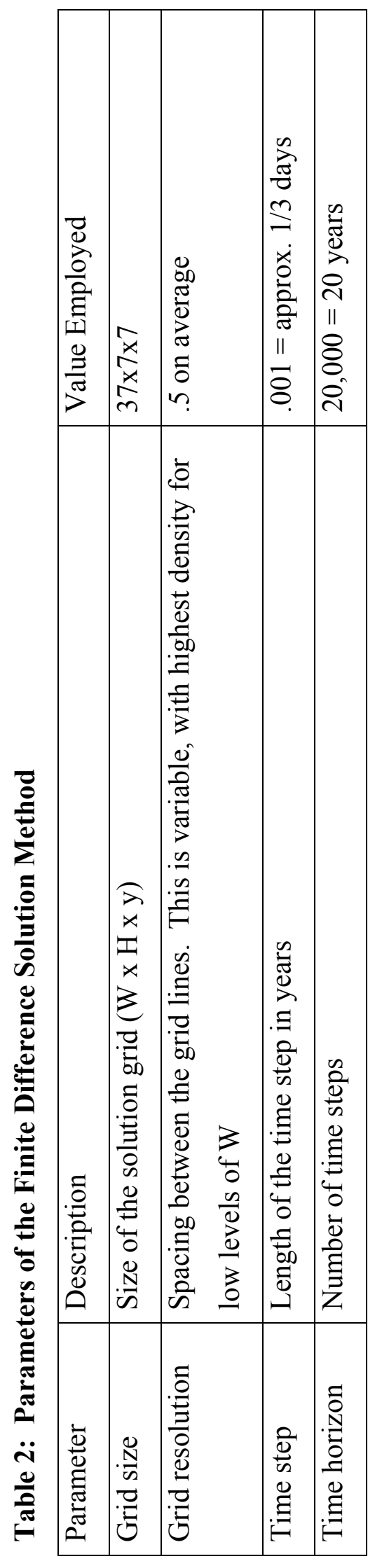




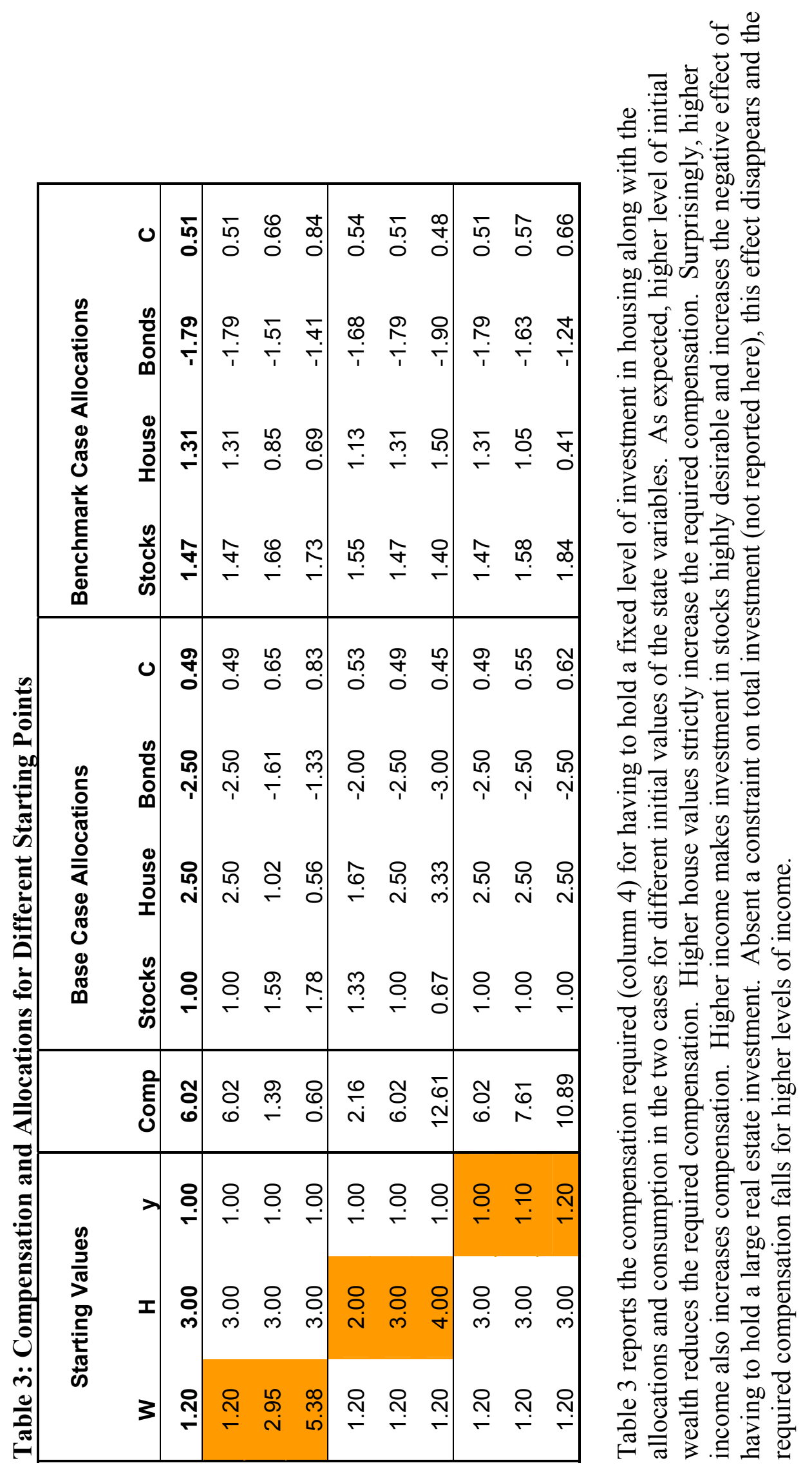

